\title{
CONEXIÓN INSTITUCIONAL NECESARIA: «DESARROLLO»DE LOS DERECHOS CIVILES PROPIOS EN LA ÚLTIMA JURISPRUDENCIA DEL TRIBUNAL CONSTITUCIONAL
}

\author{
Necessary institutional connection: "Development" \\ of the regional civil laws in the last cases \\ of the Constitutional Court
}

\author{
MARÍA ÁNGELES EGUSQUIZA BALMASEDA \\ Universidad Pública de Navarra \\ egusquiza@unavarra.es
}

Cómo citar/Citation

Egusquiza Balmaseda, M. A. (2018)

Conexión institucional necesaria: «desarrollo» de los derechos civiles propios en la última jurisprudencia del Tribunal Constitucional. Derecho Privado y Constitución, 33, 47-78. doi: https://doi.org/10.18042/cepc/dpc.33.02

(Recepción: 10/07/2018; aceptación tras revisión: 24/09/2018; publicación: 28/11/2018)

\section{Resumen}

La constante doctrina constitucional sobre la dimensión del art. 149.1.8. ${ }^{\text {a }} \mathrm{CE}$, fundada en la garantía de la foralidad, no ha eliminado la complejidad en esta materia. La exigencia de que todo "desarrollo" normativo civil deba estar ligado a una «conexión» institucional preexistente con el derecho civil propio, vinculado a sus principios, hace que la valoración de este elemento constituya una pieza clave del sistema. El trabajo repasa estas cuestiones, centrándose en la dimensión que la «conexión» institucional ha desempeñado para tachar de inconstitucional la regulación de la adopción y autotutela de la Ley de Derecho Civil de Galicia de 2006 _STC 
133/2017 - y estimar constitucionales las normas sobre bienes vacantes de la Ley Foral del Patrimonio de Navarra de 2007 _STC 40/2018 - y de la Ley del Patrimonio de Aragón de 2011 y su texto refundido de 2013 — STC 41/2018_.

\section{Palabras clave}

Derecho civil foral; competencia; comunidades autónomas; conexión institucional; adopción; autotutela; bienes vacantes; sucesión legal del Estado.

\section{Abstract}

The continuous doctrine regarding the scope of art. 149.1.8th of the Spanish Constitution, founded on the guarantee of "regionalism", hasn't yet removed the complexity of this matter. Given the requirement that every civil normative development needs to be rooted in a preexisting institutional "connection" to own Civil Law, linked to its principles, the evaluation of this element entails a key aspect of the system. These questions are assessed in the paper, focusing on the scope that this institutional "connection" has reached in order to consider the regulation on adoption and self-guardianship in the 2006 Civil Law of Galicia as inconstitutional - STC 133/2017 - and deeming constitutional the regulation on vacant goods in the 2007 Foral Law of Patrimony of Navarra —STC 40/2018 — as well as the 2011 Law of Patrimony of Aragon and its 2013 revised text —STC 41/2018-.

\section{Keywords}

Special or Regional Civil Law; competence; autonomous communities; institutional connection; adoption; self-guardianship; vacant goods; State legal succession. 


\section{SUMARIO}

I. ALGUNAS CONSIDERACIONES PREVIAS. II. LA DIMENSIÓN DEL ARTÍCULO 149.1.8 CE: GARANTÍA DE LA FORALIDAD. III. LA «CONEXIÓN INSTITUCIONAL» EN MATERIA DE ADOPCIÓN Y AUTOTUTELA. LA DECLARACIÓN DE INCONSTITUCIONALIDAD DE LA STC 133/2017: 1. La confianza del camino seguido en otros derechos civiles forales o especiales. 2. Necesidad de una "conexión institucional específica» versus "conexión institucional orgánica» en materia de adopción y autotutela. IV. LEGISLACIÓN NAVARRA Y ARAGONESA SOBRE PROPIEDAD VACANTE: SU CONSTITUCIONALIDAD CONFORME A LAS SSTC 40/2018 Y 41/2018, 26 DE ABRIL: 1. Competencia legislativa civil como fundamento del desarrollo normativo sobre bienes mostrencos o propiedad vacante. 2. Conexión «orgánica» o «institucional» para el «desarrollo» normativo sobre bienes vacantes: 2.1. Justificación de los arts. 15 y 16 de la Ley Foral 14/2007: Ilamamiento legal a la Comunidad Foral y régimen patrimonial del Fuero Nuevo de Navarra. 2.2. Disposición adicional sexta de la Ley 5/201 1, de 10 de marzo, del Patrimonio de Aragón, y texto refundido de 2013: conexión institucional de los bienes abintestato «versus» bienes abandonados. V. BREVE REFLEXIÓN FINAL. BIBLIOGRAFíA.

\section{ALGUNAS CONSIDERACIONES PREVIAS}

A pesar del tiempo transcurrido y la existencia de un núcleo asentado de jurisprudencia constitucional, que ha definido el alcance de la competencia legislativa civil que reconoce el artículo $149.1 .8 .^{a} \mathrm{CE}$, no se ha logrado que las actuaciones de los legisladores autonómicos sobre legislación civil sean un tema pacífico y ofrezcan unos contornos previsibles y ciertos.

Los factores que han motivado este estado de cosas tienen un origen y etiología diversos ${ }^{1}$, que sintéticamente se pueden resumir en los siguientes aspectos.

1) La diversidad de criterios sobre el alcance que debiera darse al artículo 149.1.8. ${ }^{a} \mathrm{CE}$ en cuanto al sistema de atribución de la competencia legislativa

1 La bibliografía sobre la materia es abundante, entre los trabajos recientes cabe citar: Egusquiza Balmaseda (2007: 238-240); Arroyo Amayuelas (2010: 178); Acedo Penco (2010: 252 y ss.); García Rubio (2017: 2 y ss.) 
civil. La fijación por el Tribunal Constitucional de un cuerpo de doctrina constante sobre las nociones de "conservación, modificación y desarrollo" del derecho civil propio, iniciado con la STC 88/1993, no ha evitado su cuestionamiento. Las discrepancias de los propios guardianes de la interpretación del precepto constitucional, presente ya en los votos particulares de la citada sentencia, o la búsqueda por algunas comunidades autónomas de un nicho de actuación competencial más allá de los términos del artículo 149.1.8 a ${ }^{a} \mathrm{CE}$, a través de la modificación de sus normas estatutarias, han sido dos elementos cruciales en este proceso.

El desarrollo legislativo civil acometido por la Comunidad Valenciana constituye un ejemplo de ello. Con la reforma del art. 7 de su estatuto de autonomía, que proclamaba «la recuperación de los contenidos correspondientes de los Fueros del histórico Reino de Valencia», sin tacha de inconstitucional, se justificó el crecimiento normativo sobre el régimen económico matrimonial, las relaciones familiares y las uniones de hecho; leyes declaradas inconstitucionales por su extralimitación competencial —SSTC 82/2016, 192/2016, 110/2016 - Otro caso significativo ha sido la reforma introducida en el art. 129 del Estatuto de Autonomía de Cataluña por la Ley Orgánica 6/2006, cuyo tenor pasó a expresar que "corresponde a la Generalitat la competencia exclusiva en materia de Derecho civil, con excepción de las materias que el artículo 149.1.8 a de la Constitución atribuye en todo caso al Estado", y «la determinación del sistema de fuentes del Derecho civil de Cataluña». La STC 31/2010 estimó, con cinco votos discrepantes, que el precepto estatutario era constitucional siempre que se interpretase en el sentido de que la "competencia exclusiva en materia de Derecho civil» se ciñe estrictamente a la «conservación, modificación y desarrollo del Derecho civil catalán», que son "la medida y el límite primero de las competencias atribuibles y ejercitables por las Comunidades Autónomas en virtud del art. 149.1. 8a CE» (FJ 7633).

2) La convivencia de leyes civiles forales o especiales de contenido semejante, con tacha de inconstitucionalidad unas y otras no, por no haber sido impugnadas (Arroyo Amayuelas, 2010: 178) o excluírseles de ese control al retirarse por razones políticas los recursos de inconstitucionalidad interpuestos contra ellas ${ }^{4}$. Aboca también a esta situación la discusión sobre los límites

2 Véanse, entre otros, Amat Llombart (2017: 9 y ss.); De Verda y Beamonte (2017: 111 y ss.); Palao Gil (2017:163 y ss.), Bercovitz Rodríguez-Cano (2016 y 2017).

3 Entienden incongruente este pronunciamiento, entre otros, Badosa Coll (2010: 332 y 339) y Egea Fernández (2010: 340 y ss.).

4 Ejemplo reciente y significativo es la introducción por la Ley 5/2015, de 25 junio, de Derecho Civil del País Vasco, de un régimen en el ámbito sucesorio, que no ha sido 
de los órganos jurisdiccionales en la valoración de la constitucionalidad de las leyes posconstitucionales, decisión reservada en exclusiva al Tribunal Constitucional (STC 195/2015); ya que, en tales casos, la depuración del sistema depende de la energía, tiempo y sensibilidad de los operadores jurídicos en el planteamiento de la pertinente cuestión de inconstitucionalidad —art. 163 $\mathrm{CE}^{5}-$.

3) La falta de pulsión del legislador estatal para adecuar la normativa civil común a los tiempos presentes. Este espacio ha sido aprovechado por los legisladores autonómicos para dar respuesta a las demandas sociales, a la vez que para extender su derecho civil propio sobre la base de sus títulos competenciales (Arroyo Amayuelas, 2010: 177 y ss.; Egusquiza Balmaseda, 2007: 238-240). A ello no es ajena la dificultad técnica de legislar en materia civil, así como la carencia de un rédito político inmediato de un trabajo cuyo rigor y dedicación suelen trascender los tiempos políticos, y la posible desafección de los parlamentarios estatales en acciones normativas que no interpelan a sus votantes por estar sujetos a regímenes de derecho civil foral o especial (García Rubio, 2017: 23 y ss.).

Las tres últimas sentencias dictadas en aplicación del art. 149.1.8 ${ }^{a}$ de la CE - STC 133/2017, de 16 de noviembre, y SSTC 40/2018 y 41/2018, de 26 de abril- son, sin duda, ejemplos de lo expuesto y reflejan parte de los problemas que, desde la perspectiva técnica y la pugna de visiones, suscita el reparto de competencias en materia legislativa civil. En el fondo de todas ellas late la cuestión de la extensión del ordenamiento plurilegislativo que se quiere para el sistema jurídico civil español, como parte y todo, en la tensión que sigue viva entre la garantía de la foralidad y el autonomismo legislativo civil ${ }^{6}$.

impugnado, que equipara a la pareja estable con el matrimonio — arts. 52, 54, 112, 120 LDCPV - de contenido semejante al declarado inconstitucional para Navarra por la STC 93/2013, 23 de abril.

5 Como ejemplo refiere Roca Trías (2010: 346 y ss.) las leyes catalanas de fundaciones de 1981, de Sucesión Intestada, Ley 9/1987; de Filiaciones, Ley 7/1991; de la Accesión y Ocupación, Ley 25/2001; de Derechos Reales de Garantía, Ley 19/2002, y de la primera ley del Código Civil de Cataluña, Ley 29/2002. Ajustada a la Constitución se ha entendido, por la STC 95/2017, la Ley 19/2015 de Incorporación de la Propiedad Temporal y de la Propiedad Compartida. Pendientes de resolución están los recursos de inconstitucionalidad sobre la Ley 3/2017, de 15 de febrero, del libro sexto del Código Civil de Cataluña, relativo a las obligaciones y los contratos, y de la Ley 10/2017, de 27 de junio, de las voluntades digitales y de modificación de los libros segundo y cuarto del Código Civil de Cataluña.

6 Algunos autores vienen reclamando la reforma del art. 149.1.8. ${ }^{\text {a }}$ CE considerando superadas las reglas de reparto competencial tanto para las CC. AA. históricas con 


\section{LA DIMENSIÓN DEL ARTÍCULO 149.1.8 CE: GARANTÍA DE LA FORALIDAD}

La consolidada doctrina del Tribunal Constitucional sobre la dimensión del art. 149.1.8. ${ }^{a} \mathrm{CE}$, que faculta a las CC. AA. con «Derecho civil propio» a "conservar, modificar y desarrollar» las instituciones que tenían vivas a la entrada en vigor de la CE de 1978 es el punto de partida del juicio de constitucionalidad que, con mayor o menor acierto, se ha emitido en la STC 133/2017 sobre el régimen de adopción y autotutela de la Ley de Derecho Civil de Galicia de 2006, y en las SSTC 40/2018 y 41/2018 sobre la atribución de la titularidad de los bienes vacantes recogida en la Ley de Patrimonio de Navarra de 2007 y la Ley de Patrimonio de Aragón de 2011, texto refundido del año 2013.

En todos esos pronunciamientos se reseñan los parámetros desde los que ha de valorarse la legitimidad de la actuación legislativa civil de la comunidad autónoma concernida que cuenta con competencia ex art. 149.1.8. ${ }^{a} \mathrm{CE}$ y que ponen de manifiesto los perfiles de la doctrina constitucional, ortodoxa y reiterada, sobre la materia.

Un primer aspecto es el ámbito normativo institucional. La competencia legislativa civil de las CC. AA. que cuentan con derecho civil propio no se limita a las instituciones que se hallaban recogidas en sus compilaciones de derecho civil foral o especial al momento de la entrada en vigor de la Constitución de 1978, sino que se extiende a su derecho consuetudinario. Así se recuerda en la STC 133/2017 (FJ 4) al valorar el ajuste constitucional de las regulaciones introducidas ex novo en la LDCG de 2006 sobre adopción y autotutela, con cita de la STC 182/1992 que enjuició la Ley gallega 2/1986 de Prórroga en el régimen de Arrendamientos Rústicos para Galicia. La carencia de una regla directa o indirecta en los textos compilados no es óbice para el ejercicio de la competencia legislativa civil. La posibilidad de «conservar, modificar y desarrollar» el derecho civil propio entraña, también, la «recepción y formalización legislativa de costumbres y usos efectivamente vigentes en el respectivo territorio autonómico, eventualidad, esta última, que resulta aún más clara visto el enunciado del referido artículo 27.4 EAG, pues en la idea de «institución» jurídica, presente en tal precepto, se integran o pueden integrar, con naturalidad, posibles normas consuetudinarias».

No obstante, tratándose de normas consuetudinarias, recuerda la STC 133/2017 (FJ 4) abundando en su doctrina previa — SSTC 82/2016,

derecho civil propio como para el resto. Véanse Roca Trías (2010: 35) y Ragel Sánchez (2005: 179). 
18/2004 y 127/1999—, es preciso que se cumpla una doble condición: a) la vigencia temporal de la costumbre al momento de la entrada en vigor de la Constitución, exigencia derivada del «allí donde existan», y b) la prueba de esa regla consuetudinaria, que permita el desarrollo normativo directamente o por conexión, a través de su notoriedad o por aportación probatoria de quien efectuó el desarrollo legislativo; suficiencia probatoria cuya valoración queda a criterio y arbitrio del Tribunal Constitucional.

Un segundo parámetro, a ponderar, es el reparto material de la competencia legislativa civil entre el Estado y las CC. AA. Este tiene una dimensión concreta que viene definida, en palabras del propio Tribunal Constitucional —SSTC 133/2017 (FJ 4), 40/2018 (FJ 6) y 41/2018 (FJ 4)—, por «una garantía de la foralidad civil a través de la autonomía política, garantía que no se cifra, pues, en la intangibilidad o supralegalidad de los Derechos civiles especiales o forales, sino en la previsión de que los Estatutos de las Comunidades Autónomas en cuyo territorio aquéllos rigieran a la entrada en vigor de la Constitución puedan atribuir a dichas Comunidades competencia para su "conservación, modificación y desarrollo»; lo que supone que no cabe entender en este punto de manera expansiva el artículo 149.1.8 $\mathrm{CE}$, debiéndose ajustar a las reglas que se hallan prefijadas».

La regla competencial de primer grado es la que atribuye al Estado la competencia exclusiva en materia legislativa civil, que cede ante la posible competencia de las CC. AA. que cuentan con un derecho civil propio, y se formula como una excepción a la establecida con carácter general en favor del Estado. Esta conforma los límites y la medida del reparto de la competencia en materia legislativa civil, que tiene como objetivo concreto la "garantía de la foralidad».

No constituye norma de reparto competencial de primer grado la ulterior reserva que se atribuye al Estado "en todo caso» sobre determinadas materias, señalada en la parte segunda del artículo 149.1.8. ${ }^{a} \mathrm{CE}$. Al decir del propio Tribunal Constitucional, se trata de una segunda reserva a favor del Estado que establece un límite absoluto «dentro del cual nunca podrá estimarse subsistente ni susceptible, por tanto, de conservación, modificación o desarrollo, Derecho civil especial o foral alguno».

Ello entraña, como recuerda Bercovitz Rodríguez-Cano (2018a), que los límites a la actualización y desarrollo de los derechos civiles propios no se encuentren situados en las materias de esa segunda reserva competencial a favor del Estado, sino en el posible alcance, limitado, de la previa excepción contenida en la primera parte del precepto. No cabe «una competencia legislativa civil ilimitada ratione materiae dejada a la disponibilidad de las Comunidades Autónomas» con propio derecho civil foral o especial, sin más límites que la regulación sobre «las reglas relativas a la aplicación y eficacia de las normas 
jurídicas, relaciones jurídico-civiles relativas a las formas de matrimonio, ordenación de los registros e instrumentos públicos, bases de las obligaciones contractuales, normas para resolver los conflictos de leyes y determinación de las fuentes del Derecho».

Por tanto, la competencia legislativa civil de las CC. AA. se ciñe a las materias que, conforme a la garantía de la foralidad de su derecho civil especial o foral, le correspondían a la entrada en vigor de la Constitución, que podrán conservar, modificar y desarrollar. Esta última función es la que suscita mayores controversias en su valoración constitucional.

Un tercer parámetro de análisis viene dado por el significado de los conceptos de "conservación», «modificación» y «desarrollo» del derecho civil propio, delimitado por la doctrina constitucional y que, hoy por hoy, es la pieza clave para entender el alcance competencial respecto a la legislación civil.

$\mathrm{La}$ "conservación» se identifica con la facultad que tienen las CC. AA. para que asuman o integren «las Compilaciones y otras normas derivadas de las fuentes propias de su ordenamiento», así como para formalizar legislativamente "costumbres efectivamente vigentes en el propio ámbito territorial», sin que a tal fin baste con la mera invocación de los precedentes históricos y viejas tradiciones para su positivización normativa.

El concepto de «modificación» implica la posibilidad de alterar y reforma el derecho preexistente, además de las reglas contenidas en este.

Por último, la noción de "desarrollo» (Bercovitz Rodríguez-Cano, 1993: 344; Vaquer Aloy, 1994: 323-332), cuyos parámetros han sido objeto de especial enjuiciamiento en las sentencias que nos ocupan, supone permitir «una ordenación legislativa de ámbitos hasta entonces no normados por aquel Derecho», ya que la interpretación restrictiva llevaría a la identificación de ese concepto con el más restringido de «modificación». El «desarrollo» de los derechos civiles forales o especiales no supone una vinculación rígida al contenido actual de la Compilación u otras normas de su sistema, comprende la regulación de las «instituciones conexas con las ya reguladas en la Compilación dentro de una actualización o innovación de los contenidos de ésta según los principios informadores peculiares del Derecho foral» —STC 133/2017 (FJ 4), STC 40/2018 (FJ 6) y STC 41/2018 (FJ 5)—.

El gran tema, en relación con esta cuestión, es el tipo de conexión institucional que ha de existir para valorar ajustada la regulación novedosa a los parámetros constitucionales. La pregunta que habría que responder es si esa "conexión» requiere una plena identidad institucional, o cabe su apreciación por proximidad con otras figuras, o puede estimarse desde una valoración orgánica general del sistema jurídico concernido que comprenda el derecho positivizado y la costumbre o uso que estuviese vigente al momento de la entrada en vigor de la Constitución; o, incluso, pueda explicarse sobre los particulares 
principios informadores del derecho civil referido. Ese juicio podría acotarse también en atención a la concepción dogmática de las instituciones o la funcionalidad satisfecha por las instituciones preexistes, criterios que pueden propiciar una mayor o menor competencia en la materia (Bercovitz Rodríguez-Cano, 2018b).

No cabe desconocer, como apunta Egea Fernández (2010: 344), que «una interpretación amplia del criterio constitucional de la conexión, que no la limite a las instituciones compiladas, sino que aproveche cada una de las posibilidades que ofrece la misma jurisprudencia constitucional, particularmente en el punto en que admite que la conexión se puede referir al «Derecho civil en su conjunto» (STC 88/1983, FJ 3) o a «los principios informadores peculiares del Derecho foral» materialmente faculta para que se pueda ir más allá de la "garantía de la foralidad»». En el ámbito fáctico ello haría posible que, con excepción de las materias que «en todo caso» figuran excepcionadas y reservadas al Estado en la segunda parte del art. 149.1.8 $\mathrm{CE}$, pudiera legislarse sobre el resto de las cuestiones que afectan a la materia civil.

De ahí que, hoy por hoy, la verdadera dimensión del sistema de reparto competencial para las CC. AA. con derecho civil propio se dilucide en el análisis concreto de la suficiencia de las conexiones institucionales que legitiman el desarrollo legislativo civil que, en unos casos, parece que se requiere con un rigor de vinculación y juicio de existencia que encajaría dentro de la facultad de «modificación» del derecho civil propio, mientras que en otros se acepta una conexión menos inmediata o directa, permitida o soportada sobre valoraciones del conjunto de las instituciones reguladas o los principios generales del concreto sistema jurídico. El diferente criterio empleado por el Tribunal Constitucional, a la hora de ponderar la conexión institucional que fundamenta el desarrollo de los derechos civiles propios, es el que despierta perplejidades y motiva la crítica del tratamiento desigual en esta materia; suscitando la idea de que el criterio es diverso según se enjuicie a unas u otras CC. AA. con derecho civil foral o especial.

\section{LA «CONEXIÓN INSTITUCIONAL» EN MATERIA DE ADOPCIÓN Y AUTOTUTELA. LA DECLARACIÓN DE INCONSTITUCIONALIDAD DE LA STC 133/2017}

\section{LA CONFIANZA DEL CAMINO SEGUIDO EN OTROS DERECHOS CIVILES FORALES O ESPECIALES}

Según se ha señalado (Díaz Martínez, 2008: 175 y ss.), la razón de que se incluyera la regulación de la adopción y la autotutela en la Ley 2/2006, de 
14 de junio, de Derecho Civil de Galicia —arts. 27 a 45-, sin precedente en su legislación civil anterior —Compilación de 1963, Ley 7/1987 y Ley 4/1995-, se debió a que se contaba con una cierta regulación autonómica sobre esas materias, fundada en la competencia sobre la asistencia social y promoción al desarrollo (art. 27, apdos. 23 y 24 EAG).

La regulación de la adopción se acometió por la LDCG de 2006, asumiendo las previsiones contenidas en la Ley 3/1997, de 9 de junio, de protección jurídica, económica y social de la familia, la infancia y la adolescencia, que regulaba la declaración de desamparo, tutela automática de la Administración, guarda administrativa, acogimiento y procedimiento de adopción. A esta regulación se añadieron otros aspectos «jurídico-privados» a fin de ofrecer un régimen completo sobre los requisitos impuestos a adoptantes y adoptandos, prohibiciones, efectos y extinción en la adopción. La dificultad que entrañaba que una regulación dictada en virtud de la competencia sobre asistencia social pudiera llevar a disciplinar los aspectos institucionales de corte civil, se consideró que podía superarse en virtud de la existencia, en la tradición jurídica gallega, de figuras conectadas con el fin institucional de la adopción, el «afillamento» o prohijamiento y la "perfiliato» o perfiliación, que justificarían la necesaria competencia en materia civil para acometer ese desarrollo (Díaz Martínez, 2008: 179 y ss.; Sarmiento Méndez, 2007; Álvarez Lata, 2008: 63; Rebolledo Varela, 2000: 1702).

La disciplina de la autotutela se entendía vinculada al ámbito asistencial de la persona y diseño preventivo de los instrumentos de protección del futuro incapacitado —art. 27.26 EAG (Nieto Alonso, 2008: 237 y ss.)—, así como a las instituciones y los principios propios de protección del patrimonio y la persona del ámbito civil, presentes en el desenvolvimiento de las instituciones familiares y sucesorias gallegas; esto es: a) el principio de autonomía privada, base de las especialidades sucesorias gallegas; b) los mecanismos de autoprotección de la tradición jurídica gallega — contrato de vitalicio e institución de heredero a cuidado del testador-; c) la regulación sobre voluntades anticipadas de la Ley gallega 3/2001, de 28 de mayo, reguladora del consentimiento informado y de la historia clínica de los pacientes, y d) el régimen de la ausencia no declarada prevista en la LDCG de 1995 (Álvarez Lata, 2008: 81-85). Todos ellos ofrecerían un soporte plausible de conexión institucional con la regulación de la autotutela, conforme a la visión del Tribunal Constitucional de "desarrollo» legislativo civil ex art. 149.1.8. ${ }^{a} \mathrm{CE}$.

Al margen de las consideraciones de política general sobre la oportunidad o conveniencia de que cada comunidad autónoma con derecho civil propio, en el ejercicio de sus competencias, amplíe su normativa civil reiterando el régimen del Código Civil, y la valoración de si cabe apreciar en tal caso que median especialidades en el derecho civil propio que hagan necesario 
un régimen legal diferenciado ${ }^{7}$, cabe preguntarse si las expectativas del legislador gallego de superar el examen de constitucionalidad podían considerarse a priori justificadas.

Un primer dato con el que se contaba, y que fue esgrimido en la contestación al recurso de inconstitucional, era el precedente de la STC 88/1993, que había reconocido la competencia legislativa civil sobre la adopción a la Comunidad Autónoma de Aragón y estimado constitucional su Ley 3/1988, de 25 de abril, de Equiparación de los Hijos Adoptivos, a pesar de que dicha institución fuera ajena a la Compilación de Derecho Civil aragonés. Esta regulación se ceñía a un aspecto concreto, la equiparación en efectos de los hijos adoptivos a los hijos por naturaleza, no perseguía fijar una disciplina de la adopción en su conjunto. En este caso el juicio favorable del Tribunal Constitucional devino del entendimiento de que mediaba una indiscutible conexión del status familiae del adoptado con las instituciones reguladas en su Compilación civil, hallándose esa disciplina vinculada a sus previsiones sobre relaciones entre ascendientes y descendientes, relaciones parentales y tutelares, y la disciplina del derecho de sucesión por causa de muerte.

En ese sentido, enjuiciaba Álvarez Lata, si el Tribunal Constitucional aceptó como «indiscutible» la conexión institucional cuando la regulación aragonesa sobre la adopción ni conservaba un hipotético derecho consuetudinario ni modificaba el derecho aragonés preexistente, sino que lo desarrollaba sobre la base de la conexión existente entre el derecho aragonés y el nuevo instituto, resultaría ciertamente incomprensible que se estimara en este punto el recurso de inconstitucionalidad interpuesto contra la LDCG, teniendo en cuenta además el tiempo transcurrido y lo acontecido desde entonces en el panorama de los derechos civiles autonómicos (Álvarez Lata, 2008: 73).

Un segundo aspecto ponderable devenía del hecho de que la adopción y la autotutela habían sido objeto de tratamiento legislativo por el legislador catalán (Ley 37/1991, de 30 diciembre, sobre medidas de protección de los

Sobre este punto Álvarez Lata (2008: 74 y ss.) había apuntado: «Se pierde la oportunidad de dar sentido a la regulación de la adopción en el Derecho gallego reflejando normativamente en algunos preceptos las especialidades propias que se reivindican precisamente para legislar en la materia. Ello se advierte, en especial, en el art. 28 LDCG, que reproduce prácticamente el art. $175.2^{\circ} \mathrm{CC}$ en lugar de sentar alguna diferencia respecto de la adopción del mayor de edad que ha sido afillado sin perder los vínculos con su familia natural o en el art. 34 LDCG al regular los casos en los que no se requiere propuesta de la entidad pública para la constitución de la adopción que tampoco introduce una excepción que reflejara la práctica gallega del afillamento en el sentido que se vio, de quien acoge en casa, aun sin las formalidades legales, para transmitírsela luego o hacerlo heredero». 
menores desamparados y la adopción, y Ley 39/1991, de 30 de diciembre, de la Tutela y las Instituciones Tutelares, refundidas en el Código de Familia de 1998 — arts. 115 a 131 y 172 a 177 - , y actualmente recogidas en los arts. 235-30 a 235-52 y 222-4 a 222-9 del Código Civil catalán); así como, en cuanto a la autotutela, por el legislador aragonés (art. 108 de la Ley 13/2006, de 27 de diciembre, de Derecho de la Persona, y del vigente Código de Derecho Foral de Aragón de 2011) (Nieto Alonso, 2008: 240 y ss.). De tales normativas no se cuestionó su constitucionalidad y son plenamente aplicables.

Ese carente reproche competencial pudo hacer pensar en la suficiencia del título para acometerlas, aunque se partiera de condiciones institucionales diferentes. En materia de adopción, el artículo sexto de la Compilación catalana de 1960 ya reflejaba un régimen singular sobre la adopción que, fiel a sus raíces históricas, excluía la prohibición impuesta en el Código Civil de adoptar a quienes tuvieran descendencia; restricción suprimida por la legislación estatal de 1970 sobre adopción (Bercovitz Rodríguez-Cano, 1971: 932). En cuanto a Aragón, el art. 15 de su Compilación de Derecho Civil de 1967 contenía un régimen propio para la delación de la tutela.

$\mathrm{El}$ argumento descrito se deja entrever en el segundo voto particular a la STC 133/2017, que, en cuanto a la disciplina de la autotutela gallega, apunta que «una regulación similar sobre la autotutela se incluye pacíficamente en el Código civil de Cataluña y [...] se fundamenta sin discusión en la competencia legislativa autonómica en materia civil».

Hay una última cuestión que, a mi juicio, pudo haber pesado en el ánimo del legislador gallego. Esta tiene que ver con la transversalidad de las materias objeto de desarrollo en las que la intervención de la Administración está presente y no siempre resulta nítida la frontera entre lo que puede considerarse propiamente civil y administrativo. A estos efectos basta pensar en la regulación que el propio Código Civil establece sobre la tutela automática, el desamparo, el acogimiento — arts. 172 a 175 - o el régimen de idoneidad de la adopción —art. 176.3 —, normas de un perfil ambivalente.

La voluntad de que una regulación sea sistemática y eficiente puede abocar a que no se visualice de una forma nítida la necesidad de mantener algunas regulaciones en compartimentos estancos, cuando la frontera no es tan clara. A esta apreciación contribuye la propia doctrina del Tribunal Constitucional, que ha reconocido, en algunas ocasiones, que la regulación administrativa de una institución faculta cierta capacidad para disciplinar sus aspectos jurídico-privados (caso de la asociación, STC 173/1998 o STC 135/2006). La aceptación, sin mayor cuestionamiento, de que las CC. AA. con competencia legislativa civil poseen legitimación para regular los aspectos jurídico-civiles de ciertas realidades sociales, como las parejas estables o uniones hecho - STC 
93/2013, STC 81/2013 o STC 110/2016-, pudo hacer pensar que no sería cuestionado un desarrollo legislativo civil como el acometido.

\section{NECESIDAD DE UNA "CONEXIÓN INSTITUCIONAL ESPECÍFICA» VERSUS «CONEXIÓN INSTITUCIONAL ORGÁNICA» EN MATERIA DE ADOPCIÓN Y AUTOTUTELA}

Esta es la cuestión central debatida en la STC 133/2017 y sobre la que se soporta la tacha de inconstitucional de la regulación introducida en la LDCG de 2006 sobre la adopción y autotutela. El tema se suscita no solo por la vinculación del desarrollo normativo a las normas positivas del derecho civil de Galicia, sino fundamental y específicamente por la apreciación de tal conexión a instituciones consuetudinarias no positivizadas, una de sus particularidades «más relevantes y que informa tal ordenamiento civil» —STC 133/2017 (FJ 4 - - Ello enfrenta un problema previo, que es la valoración de la vigencia del uso o costumbre «allí donde exista»; prerrequisito para la ulterior apreciación de la legitimidad del desarrollo legislativo civil en la materia.

La introducción de una regulación positiva completa de la adopción en la LDCG de 2006, semejante a la que recogía en aquel entonces el Código Civil, e inclusión de la figura de la autotutela, sin que la exposición de motivos de la citada ley vinculara esas figuras a ninguna institución consuetudinaria ni especialidad foral gallega, ha llevado a que se considere en la STC $133 / 2017$ que esas disposiciones no formalizaban normas consuetudinarias sino que incluían una regulación ex novo. Se admite, con todo, la posibilidad del desarrollo legislativo desde esas prácticas e instituciones consuetudinarias conexas, aunque para ello se requiere la acreditación de su existencia cuando se invocan, "salvo que sean notorias, precisamente para distinguirlas de los meros usos sociales o convencionales, del mero hábito».

Cabe recordarse que el art. 2 de LDCG dispone que «los usos y costumbres notorios» no requieren prueba; y que son notorios «los usos y costumbres compilados» - ley y no costumbre ${ }^{8}$ —, así como «los aplicados por el Tribunal Supremo, el Tribunal Superior de Justicia de Galicia o la antigua Audiencia Territorial de Galicia».

Las instituciones conexas que, vinculadas a los principios propios del derecho civil de Galicia, se adujeron como justificativas de ese desarrollo normativo eran las figuras tradicionales de «la casa» o «la compañía familiar

8 Sande García (2008: 69) pone de relieve este aspecto e inutilidad de denunciar la infracción de una costumbre cuando se ha positivizado (SSTSJ de Galicia 14/2001, de 15 de junio [RJ 2001, 6543], y 4/2006, de 23 de enero [RJ 2006, 844]). 
gallega», sobre la que pivotan instituciones familiares y sucesorias típicas de esa comunidad, tendentes a su mantenimiento o no fragmentación, así como la antigua normativa sobre casas de acogida y práctica del prohijamiento (afillamento) o perfiliación (perfilatio), que permitían, a quienes carecían de descendencia, encontrar un heredero y preservar la unidad de la casa y explotación económica.

Para los magistrados que han suscrito la STC 133/2017, estas instituciones y prácticas consuetudinarias — cuya vigencia no se cuestionaba — carecían de la conectividad institucional necesaria para legitimar la regulación de la adopción. La casa y la compañía familiar gallega se descartan como posible anclaje en atención a que "poseen un carácter marcadamente patrimonial, alejado, pues, de los fines y fundamento de la adopción", aun cuando se reconoce que aquellas son una manifestación singular de la forma de preservación de valores familiares y constitución tradicional de la familia. La invocación de la existencia de una antigua normativa sobre casas de acogida se rechaza también en virtud de que "«ésta no acredita la existencia de costumbres relativas a la adopción sino la prestación asistencial de la Comunidad a situaciones de desamparo o vulnerabilidad que, desde el punto de vista competencial, se incardina más bien en la materia de asistencia social e incide en las funciones atribuidas a las entidades públicas». Este razonamiento se apoya «en que numerosas Comunidades Autónomas que carecen de Derecho civil propio ha[n] regulado la tutela administrativa y promocionado la tutela ordinaria, por lo que esta regulación, por sí sola, resulta insuficiente para erigirse como institución conexa» (FJ 4).

En cuanto a la práctica del prohijamiento (afillamento) o perfiliación (perfilatio) se dirá que «los usos históricamente practicados en el territorio gallego en torno al mismo, conectados a las instituciones agrícolas y familiares precitadas, dirigidas nuevamente al mantenimiento y continuidad de las pequeñas explotaciones agrícolas, no revelan conexión con la institución de la adopción [...] apuntan a una solución convencional, más próxima a las relaciones de trabajo o sociedad que a la institución objeto de análisis».

Esas son las bases en las que se fundamenta la inconstitucionalidad del régimen de la adopción de los arts. 24 a 42 de la LDCG de 2006, concluyéndose que «no se ha acreditado de forma fehaciente por las partes interesadas, la existencia de costumbres relativas a una forma específica de adopción u otra institución similar, en el territorio gallego al tiempo de la entrada en vigor de la Constitución».

En realidad, el reproche de inconstitucionalidad no se refiere a una falta de acreditación de las costumbres o instituciones que permitieran el desarrollo de esas figuras, sino a la valoración de la insuficiencia de conexidad de las invocadas y la exigencia de que se contara con una regulación específica 
preexistente sobre adopción. Tal valoración, a mi modo de ver, presenta algunos flancos endebles, como se ha puesto de relieve en los dos votos discrepantes de cuatro de los magistrados que conformaron la sala del Tribunal Constitucional.

Por un lado, como se indica en el voto particular primero, la conexión que se exige en la STC 133/2017 para el desarrollo del derecho civil propio no se refiere «al conjunto del ordenamiento a comparar», sino a una concreta institución civil, la de la adopción. Con ello se altera la doctrina dibujada desde sus inicios por el Tribunal Constitucional relativa a la posibilidad de que se acepte el «desarrollo» del derecho civil propio cuando se cuenta con una conexión orgánica referida al conjunto de las materias contenidas en las compilaciones o las mantenidas consuetudinariamente. Este aspecto se resalta en el segundo voto particular, comparando la decisión mayoritaria contenida en esta STC 133/2017 con la precedente, adoptada en la STC 95/2017, en la que el mismo Tribunal entendió constitucional la regulación sobre la propiedad temporal, incluida en el libro quinto del Código Civil de Cataluña, aludiendo que

[...] la competencia legislativa autonómica de desarrollo del Derecho civil propio comprende la disciplina de instituciones civiles no preexistentes, siempre y cuando pueda apreciarse alguna conexión con aquel Derecho, criterio de la conexión que, según la función que hemos señalado que realiza esta competencia legislativa autonómica, debe ir referido al Derecho civil propio en su conjunto, esto es, que se puede verificar respecto de otra institución que sí formase parte del mismo o en relación a los principios jurídicos que lo informan (FJ 4) — sustitución fideicomisaria, legado bajo condición o término resolutorio, donaciones condicionales, a plazo o reversión, compraventa a carta de gracia y enfiteusis-.

Los dos votos particulares inciden, también, en que la STC 133/2017 se aparta del criterio fijado por la STC 88/1993, en cuanto a la regulación de la adopción por el legislador aragonés, cuya legitimidad se vinculó genéricamente al derecho familiar y sucesorio de esa comunidad; apreciación que no deja de ser cierta, aun cuando dicha regulación tuviera un alcance más limitado.

En cuanto a la calificación del prohijamiento (afillamento) o perfiliación (perfilatio) como figuras más próximas a las relaciones de trabajo o sociedad que a la adopción señalaría, por mi parte, que ello supone desconocer la realidad práctica de esas instituciones y su conexión con la adopción, en la cambiante evolución que esta última ha tenido a lo largo del tiempo y su proyección en Galicia. Como apunta el segundo voto particular, la STC 133/2017 parte de «una concepción individualista ajena a los Derechos forales y más propia del régimen del Código civil, y [...] contradicen el entendimiento 
mayoritario de los juristas y antropólogos, que las consideran instituciones familiares o relacionadas con estrategias sucesorias y familiares dirigidas a conservar la unidad de la casa».

La STC 133/2017 proyecta la actual visión que se tiene de la adopción a pesar de ser una figura que se ha transformado profundamente como fenómeno y relación. Como reflexión, cabe apuntar, que la adopción en la regulación originaria del Código Civil de 1889 implicaba para el adoptante la atribución de la patria potestad sobre el adoptado menor de edad, la posibilidad de uso por este del apellido de la familia de aquel y la obligación de alimentos recíprocos; no mediaban derechos sucesorios entre ambos, aunque sí cabía pactar en la escritura de adopción la obligación de instituir al adoptando como heredero. Su reforma por la Ley de 24 de abril de 1958 llevó a distinguir dos clases de adopción: la menos plena, cuyos efectos eran semejantes a los fijados inicialmente en el Código Civil, y la plena, que atribuiría al adoptando los apellidos del adoptante y el derecho a la legítima. Con la Ley de 4 de julio de 1970 se eliminaría la prohibición de adoptar a quienes carecían de descendencia y, manteniendo las diferencias entre la adopción plena y la menos plena, llamada simple, se atribuiría a la primera los efectos de la filiación legítima y a la segunda, los de la natural (Lacruz Berdejo, 1984: 680 y ss.; Bercovitz Rodríguez-Cano, 1971: 929 y ss.; García Cantero, 1971: 789 y ss.). Solo a partir de 1981 se equiparó la «adopción plena» a la «filiación por naturaleza» —art. 108, párr. 2. ${ }^{\circ} \mathrm{CC}$ - y hasta la Ley de 11 de noviembre de 1987 no se eliminó la categorización en la adopción — plena y menos plena o simple- Tal modificación se justificó, en la exposición de motivos de la ley de 1987, en que la institución de la adopción «no ha llegado a satisfacer plenamente la función social que debe cumplir», para lo cual se introduce el régimen de «acogimiento familiar», que podía ser preadoptivo y paso previo para la adopción?. A partir de ese momento la adopción cambió su carácter contractual, se constituyó por resolución judicial, y ha conformado un vínculo pleno de filiación. Las innovaciones introducidas en el Código Civil por la Ley 26/2015, con la adopción abierta, hacen reflexionar sobre la institución y el regreso a los orígenes.

Álvarez Lata (2008: 64 y ss.), comentando el recurso de inconstitucionalidad que ha dado lugar a la STC 133/2017, señalaba que no se confundía el legislador gallego cuando en el preámbulo de la LDCG 2006 califica la adopción como una institución que «realmente estuviera viva en el Derecho

9 Cabe recordar que las previsiones del art. 172, párr. 2. ${ }^{\circ}$ del CC, introducidas por la ley de 1970, facultaban para que «la adopción simple» se pudiera convertir en plena «si concurren los requisitos exigidos para ésta». 
civil propio», a pesar de la inexplicable parquedad en su justificación. A este respecto se hacía eco de los numerosos trabajos doctrinales antropológicos y etnográficos en los que se menciona el hecho económico-jurídico basado en la adopción, en los que se alude a la adopción, prohijamiento o afillamento como elementos de un fenómeno ligado a la estructura económico familiar de Galicia y sus principios sucesorios, vinculados a la casa y la compañía familiar gallega; instituciones de honda raigambre en el derecho civil de Galicia y con regulación expresa, en el caso de la "compañía familiar gallega», en la Compilación de Derecho Civil de 1963. Tales prácticas eran concomitantes con las existentes en otros derechos civiles del norte de la Península y perseguían preservar la unidad de la casa y la búsqueda de un heredero en el caso de matrimonios sin descendencia, a fin de que no se perdiera el «apellido de la casa» o para "que no se deshaga la casa». Una situación de hecho en la que los adoptados, prohijados o «afillados» no llegaban a romper con la familia natural por las formalidades exigidas por la ley, en virtud de las limitaciones fijadas a los adoptantes por tener descendencia legítima, no cumplir con la edad requerida u otras. Ello encaja, afirma Díaz Martínez, con la realidad normativa existente sobre la adopción a la entrada en vigor de la Constitución, que diferenciaba los efectos entre adopción simple y plena, lo que acreditaría la realidad y vigencia de esa institución consuetudinaria en la sociedad gallega, probando la conexión institucional exigida para su regulación (Díaz Martínez, 2008: 180).

Las apreciaciones señaladas evocan la realidad vivida en Navarra en la que la unidad y continuidad de la "casa» - ley $48 \mathrm{FNN}$ - institución presente en la zona de la montaña, ha facultado la indivisión de las explotaciones agrarias y su eficiencia, siendo uno de los ejes vertebradores del derecho civil navarro, inspirador de una parte de sus instituciones familiares y sucesorias. Conectada a esta realidad, el Fuero Nuevo de Navarra ha regulado, desde sus inicios, en su ley 73 el "prohijamiento" y la "adopción», equiparando la primera a la adopción simple o menos plena cuando se prolongaba en el tiempo —diez años— (Fernández Urzainqui, 1990: 81 y ss.).

Desde la concepción dogmática de las instituciones reseñadas y la funcionalidad descrita parece que no resulta tan evidente la total desconexión institucional que sostiene la STC 133/2017 entre la figura del prohijamiento o «afillamiento» respecto de la adopción para justificar la tacha de inconstitucionalidad. El prohijamiento o "afillamiento" ha sido un mecanismo de integración familiar concebido fundamentalmente en beneficio de los menores en situación de desamparo bajo tutela legal de las entidades públicas, con una vocación natural de permanencia tendente a integrar de por vida al prohijado en el seno de una familia y que podía suponer que el prohijante ejerciera sobre el prohijado las funciones propias de la patria potestad, aspectos que 
diferencian esa figura del acogimiento familiar (Fernández Urzainqui, 1990: 83; Ruiz-Rico Ruiz-Morón, 2002: 219-220).

No extraña, por tanto, la discrepancia de los dos votos particulares respecto del juicio de la «falta de acreditación» de conexión institucional suficiente para el «desarrollo» legislativo civil, contradictorio con el formulado en la STC 88/1993, y de solo posible superación si se hubiera contado con un régimen previo, específico y propio sobre la «adopción» como el dispuesto en la Compilación de Cataluña de 1960 y el Fuero Nuevo de Navarra de 1973.

Para los magistrados que suscribieron los dos votos particulares existe, en este caso, el anclaje institucional necesario. El legislador gallego, dirán, contaba con justificación para el desarrollo normativo sobre la adopción en

[...] los usos históricamente practicados en el territorio gallego sobre el afillamiento conectados a instituciones familiares tan arraigadas y posteriormente cristalizadas en normas legales como la casa y la compañía familiar, que acogen en su seno a personas de distintos orígenes, asumiendo las obligaciones inherentes a las relaciones familiares y conformando la más amplia gama de estructuras personales y familiares, el derecho de labrar y poseer, la millora, la comunidad a mesa y mantel o a las normas consuetudinarias sucesorias (dirigidas todas ellas a lograr la integridad y continuidad de la casa), [que] revelan la conexión orgánica necesaria con su particular ordenamiento civil y la consiguiente competencia del legislador autonómico para regular este instituto.

Se afirma en el segundo voto particular, además, que

[...] el prohijamiento no es más que una modalidad de adopción [...]. La circunstancia de que la regulación de la adopción plasmada en la Ley impugnada no refleje las especialidades propias de esas instituciones en el Derecho consuetudinario gallego, sino que siga de cerca a los artículos del Código civil, no afecta a la validez de dicha regulación desde la perspectiva jurídico-competencial, pues lo que exige el artículo 149.1.8 CE de acuerdo con la doctrina constitucional es una conexión, no una congruencia plena con las peculiaridades históricas.

Esta última manifestación lleva a reflexionar sobre el alcance real que tiene para el Tribunal Constitucional la exigencia de que las leyes civiles de las CC. AA. deban responder a principios propios y diferentes de los vigentes en la legislación estatal, aspecto generalmente obviado en el juicio positivo de constitucionalidad —STC 95/2017— (Bercovitz Rodríguez-Cano, 2018b: 3).

Suscita, igualmente, algunas dudas la argumentación que ofrece la STC 133/2017 sobre la tacha de inconstitucionalidad del régimen de la autotutela de la LDCG de 2006. 
Para el Tribunal Constitucional la carente conexión institucional en este ámbito se funda en que «la figura de la autotutela se basa en el principio de autonomía de la voluntad, pues permite al individuo, en previsión de una eventual incapacidad, dejar designado libremente quién desea que ejerza el cargo de tutor de su propia persona", lo que implica el libre desarrollo de la personalidad; pero afirma que ello «no se encuentra reflejado en ninguna especialidad del ordenamiento jurídico gallego». Se niega ese vínculo de conexión con el sistema sucesorio de Galicia (arts. 209 a 213 LDCG de 2006) y las disposiciones testamentarias específicas a favor de las personas que cuidaron al testador (arts. 203 y 204 LDCG), afirmando que ninguna de esas instituciones "puede rectamente considerarse un instrumento de autoprotección de la persona, a los que la autotutela venga a sumarse con un natural encaje, como facultad del individuo de autogestionar sus propios intereses».

Se rechaza, asimismo, la regulación de la situación de ausencia no declarada judicialmente como anclaje institucional, figura acogida en la derogada LDCG de 1995, dado de que "la autotutela, permite a la persona autorregular sus intereses para el caso de que en el futuro se vea impedida de gobernarse por sí misma», mientras que en la "situación legal de ausencia, es la propia ley la que arbitra el mecanismo, no estando presente ni en juego el principio de autonomía de la voluntad o del libre desarrollo de la personalidad».

Por último, se argumenta discursivamente sobre la posible conexión de la autotutela con la Ley gallega 3/2001, de 28 de mayo, Reguladora del Consentimiento Informado y de la Historia Clínica, que regula las voluntades anticipadas y el consentimiento por sustitución, rechazándose aquella en virtud del título competencial en el que se fundamenta esta (sanidad, art. 33 EAG y art. 148.1.21 CE) y su carácter ajeno al derecho civil escrito de Galicia, sus costumbres o principios tradicionales.

Como se aprecia por lo señalado, la sentencia exige de nuevo para valorar el ajuste competencial de la regulación sobre la «autotutela» a los dictados constitucionales una conexión institucional que únicamente parece posible por la preexistente coincidencia institucional. En este caso tampoco le basta al legislador autonómico con una conexión orgánica general para lograr un juicio positivo, a pesar de haber sido ese el criterio en la STC 95/2017 para estimar suficiente el anclaje de la regulación catalana de la propiedad temporal y la propiedad compartida con la enfiteusis y la sustitución fideicomisaria, entendida en el segundo voto particular como una "conexión que en absoluto es más fuerte que la que presentan las instituciones de la adopción y la autotutela con determinadas figuras tradicionales del Derecho gallego». 
La desvinculación que realiza la sentencia de la proyección del principio de autonomía de la voluntad, según incida sobre la autotutela o las «disposiciones de última voluntad», no parece que pueda tener la total ajenidad que se pretende. Las instrucciones previas sobre la persona y patrimonio, plasmadas documentalmente para el caso de una futura situación de incapacidad, no solo no son extrañas sino que pueden resultar coincidentes a las que, en previsión de tal situación, se incluyan en el testamento o pacto sucesorio. Basta pensar, como se indica en los dos votos particulares, que estas constituyen "previsiones hechas por el testador para después de su fallecimiento y que en el caso de Galicia deben incardinarse, ya en primer lugar, en su Derecho sucesorio». Su conexión funcional queda evidenciada por el hecho de que la Ley 41/2003, de 18 de noviembre, de Protección Patrimonial de las Personas con Discapacidad, introdujo, junto con la autotutela, otras regulaciones en el ámbito sucesorio para la protección de las personas con futura capacidad modificada. Como ha apuntado Álvarez Lata, el principio de autonomía privada está en la base de la autotutela y sobre ella se ha justificado la conectividad exigida por la jurisprudencia constitucional en la regulación de ella acometida por el legislador catalán (preámbulo de la Ley 9/1998, de 5 de junio) y por el legislador aragonés (principio standum est chartae, art. 95 de la Ley 13/2006, de 27 de diciembre, de Derecho de la Persona de Aragón) (Álvarez Lata, 2008: 82).

El último anclaje institucional que rechazó la STC 133/2017, la ausencia no declarada judicialmente, puede pensarse que no está tan desconectado, como se pretende, de la dimensión funcional de la autotutela. Como advierte el primer voto particular, ambas figuras persiguen un mismo objetivo: «Ofrecer una adecuada protección patrimonial a las personas que no están en situación de procurársela por sí mismas, bien por estar ausentes, como en la situación de ausencia no declarada — situación histórica notoria en Galicia-, o bien porque la persona intuye que en el futuro no estará en condiciones de gobernarse por sí misma». De ahí que se diga, en el segundo voto discrepante, que resulta reduccionista la exclusión de esa conectividad institucional, "pues la naturaleza, rectamente entendida, de la autotutela reside en la finalidad tuitiva de la persona y de su patrimonio, que son dos de los ejes del Derecho civil gallego».

Poco más cabe añadir argumentalmente a lo anteriormente referido, salvo quizá señalar que la riqueza y la complejidad de las instituciones civiles forales abocan a que el juicio sobre la dimensión de lo que constituye un desarrollo del derecho civil propio positivizado o consuetudinario implique un conocimiento y una comprensión profunda de las instituciones civiles forales desde la perspectiva del propio sistema jurídico valorado, no mediatizada por la óptica que puede proyectarse desde otros ámbitos. 


\section{LEGISLACIÓN NAVARRA Y ARAGONESA SOBRE PROPIEDAD VACANTE: SU CONSTITUCIONALIDAD CONFORME A LAS SSTC 40/2018 Y 41/2018, DE 26 DE ABRIL}

\section{COMPETENCIA LEGISLATIVA CIVIL COMO FUNDAMENTO DEL DESARROLLO NORMATIVO SOBRE BIENES MOSTRENCOS O PROPIEDAD VACANTE}

No pasaron desapercibidas las regulaciones que, sobre la base de la «conservación, modificación y desarrollo» del derecho civil propio, se incluyeron sobre determinados bienes mostrencos en la Ley Foral 14/2007, de 4 de abril, del Patrimonio de Navarra, y la Ley 5/2011, de 10 de marzo, del Patrimonio de Aragón, refundida por el Decreto Legislativo 4/2013, de 17 de diciembre. La tacha de inconstitucional se dirigió, en el caso de Navarra, a los artículos 15 y 16 de la LFPN, que atribuye la titularidad a esta comunidad foral de los inmuebles vacantes «situados en su territorio" y de los «saldos y depósitos abandonados» en «entidades financieras sitas en Navarra»; y, en cuanto a Aragón, a las disposiciones adicionales sextas de aquellas normas, que asignan a esta comunidad autónoma la titularidad de las fincas de reemplazo derivadas de la concentración parcelaria de dueño desconocido.

La discusión sobre la competencia de las CC. AA. para legislar sobre sus bienes vacantes cuenta con algunos precedentes en la jurisprudencia constitucional. En ellos se refleja el debate histórico sobre la incidencia de la Ley de Mostrencos de 1935, primero, en el derecho privado y, posteriormente, en la Ley del Patrimonio del Estado de 15 de abril de 1964 —arts. 21 y 22 respecto de la adquisición de los bienes vacantes por parte del Estado ${ }^{10}$. Ese

10 Como recuerda el FJ 7 de la STC 41/2018: «La Novísima Recopilación dedica el título XXII («De los bienes vacantes y mostrencos»), del libro X, a los bienes mostrencos, aunque no los defina. Sin embargo, no cabe duda de que el hito fundamental lo constituye la Ley de mostrencos, aprobada en 1835, que atribuye al Estado los bienes semovientes, muebles e inmuebles, derechos y prestaciones que estuvieren vacantes y sin dueño conocido por no poseerlos individuos ni corporación alguna y los denominados abintestatos. En la época de la codificación quedó desgajado el régimen de adquisición de los bienes inmuebles y muebles vacantes o sin dueño conocido. Los primeros continuaron rigiéndose por la Ley de mostrencos y, en consecuencia, siguieron siendo atribuidos al Estado; y los bienes muebles abandonados siguieron el nuevo régimen establecido por el Código civil (art. 610). La atribución al Estado como bienes patrimoniales de los inmuebles vacantes y sin dueño conocido se contempló después en el Decreto 1022/1964, de 15 de abril, por el que se aprueba el texto articulado de la Ley de bases del patrimonio del Estado (arts. 21 y 22), que expresamente derogó la Ley de 
debate, que se centró inicialmente en la naturaleza del modo de adquirir reflejado en los arts. 21 y 22 de la LPE —ocupación, atribución de un derecho a su apropiación o ministerio de la ley- (García Cantero, 1965: 55; Valladares Rascón, 1976: 391 y ss.; Pantaleón Prieto, 1987: 135; Lacruz Berdejo, 1988: 130-131; Lacruz Mantecón, 2011: 126 y ss.), devino en cuestión resuelta en los ulteriores arts. 17 y 18 de la Ley 33/2003, del Patrimonio de las Administraciones Públicas, admitiéndose por la doctrina (Chinchilla Marín, 2004: 155 y ss.; Del Pozo Sierra, 2013: 260 y ss.; Sánchez Aristi, 2000: 2439 y ss.; Lacruz Mantecón, 2012: 140 y ss.) y la jurisprudencia que suponía una adquisición ope legis (STC 204/2004). El tema de la naturaleza de esas normas y los títulos competenciales sobre los que se asienta su regulación se plantean al hilo de aquellas, e implican la valoración de las competencias de las CC. AA. para acometer el desarrollo legislativo sobre los bienes vacantes que lo sean de futuro y no de pasado, como expresamente recuerda la STC 41/2018 (FJ $\left.4^{11}\right)$.

Cabe recordar que el primer pronunciamiento que resolvió esta cuestión competencial fue la STC 58/1982 (Navas Navarro, 1994: 26 y ss.), que declaró inconstitucional el art. $11^{12}$ de la Ley 11/1981, de 7 de diciembre,

mostrencos, estando actualmente recogida en la Ley 33/2003 de 2003 (arts. 17, 18 y 20, sobre los inmuebles vacantes, saldos y depósitos, y abintestatos). Parecido camino legislativo tuvo la regulación de los bienes muebles depositados en establecimientos de crédito o financieros y su correlativa atribución al Estado, en el que se puede situar como antecedente más remoto la Ley de administración y contabilidad del Estado de 7 de julio de 1911, hasta el artículo 18 de la Ley 33/2003, de 3 de noviembre, del patrimonio de las Administraciones públicas».

11 Dice el TC a este respecto: "Sólo estarán incluidos en el ámbito de aplicación del artículo 15 de la ley impugnada los inmuebles que queden vacantes con posterioridad a su entrada en vigor, lo que afectará a los escasos supuestos en que el propietario renuncie a la propiedad, o se creen ex novo siempre que su propiedad no corresponda al Estado en aplicación de otro título más específico (así, por ejemplo, la definición de los bienes del demanio natural). Por la misma razón, resulta que, en la medida en que el artículo 16 de la Ley impugnada contempla como condición para su aplicación que los saldos y depósitos cuya titularidad se atribuye a la Comunidad Foral de Navarra estén abandonados, este requisito no se cumplirá en el caso de los saldos y depósitos que, en aplicación del artículo 18 de la Ley 33/2003 hubieran sido abandonados antes de su entrada en vigor, pues ya serían de titularidad estatal».

12 «La Generalitat puede reivindicar, de acuerdo con las leyes, los bienes inmuebles retenidos o disfrutados sin título válido por entidades o particulares. En este supuesto corresponderá a la Generalitat la prueba de su derecho y los detentadores o poseedores no podrán ser inquietados en la posesión hasta que sean vencidos en juicio por sentencia firme». 
de Patrimonio de la Generalidad de Cataluña. En esta sentencia se apuntó al establecer la dicotomía entre bienes demaniales y patrimoniales, entre otras cosas, que se "deberá respetar la legislación civil, que es competencia exclusiva del Estado». También se dijo que la regulación del precepto declarado inconstitucional —art. 11- suponía una invasión de «la legislación vigente sobre el Patrimonio del Estado [y] que la titularidad de la soberanía corresponde al Estado en su conjunto y no a ninguna de sus instituciones en concreto, los bienes vacantes podrían en principio ser atribuidos a entes distintos de la Administración Central, pero sólo el órgano que puede decidir en nombre de todo el Estado y no de una de sus partes puede modificar la actual atribución» (FJ 3 ${ }^{13}$ ). De esta argumentación se dedujo (Rodríguez Carbajo, 1985: 182) que el Tribunal Constitucional aceptaba la diferenciación, doctrinalmente realizada, entre «ocupación» y «adquisición por el Estado de los inmuebles vacantes» como modos distintos de adquirir la propiedad, ambos referidos y deslindados en el art. 609 del Código Civil, calificándose al segundo de atribución por ministerio de la ley y modo de adquirir ajeno al ámbito de la «legislación civil» del art. 149.1.8. ${ }^{a}$ CE. La histórica fricción existente entre el derecho civil "común» y "foral», que medió en esta materia con la Ley de Mostrencos de 1835, quedó así trasladada al ejercicio de la competencia legislativa civil por las CC. AA.

En fechas posteriores, la STC 150/1998 tachó de inconstitucionales los arts. 66.1.3 y 4, y 100.b) de la Ley de la Comunidad Autónoma de Castilla y León 14/1990, de 28 de noviembre, de Concentración Parcelaria, que atribuían la titularidad de las fincas vacantes a esta comunidad. El fallo se justificó en la naturaleza civil de la regulación, en general, y el destino, en particular, de los bienes vacantes, sin dueño o mostrencos, y la carencia de competencia en materia legislativa civil de la citada comunidad ex art. 149.1.8. ${ }^{a} \mathrm{CE}$.

Por su parte, la STC 204/2004 aceptó ese encuadramiento competencial al dilucidar las cuestiones de inconstitucionalidad planteadas en relación con el art. 29.2 del Real Decreto Legislativo 1091/1988, que atribuía al Estado los saldos de cuentas corrientes que no tuvieran movimiento durante veinte años en su condición de bienes abandonados, y afirmó su constitucionalidad

13 A esta argumentación se añadía: «El derecho sobre los bienes ocupados o retenidos sin título válido es una derivación de la vieja regalía, como muy claramente se manifiesta en el Decreto de Carlos III de 27 de noviembre de 1785 (Novísima Recopilación $10,22,6)$ al referirse a «los bienes mostrencos, abintestatos y vacantes que pertenecen a mi Corona [...]». Con la objetivación del poder y la fusión de los derechos mayestáticos en la noción única del poder soberano, este derecho pasa al Estado, traslación que entre nosotros se opera de manera positiva mediante la Ley de 9 de mayo de 1835 (Colección Legislativa, tomo XX, pág. 173)». 
sosteniendo que «preferir la aplicación de los saldos de cuentas corrientes abandonados a fines públicos [...] en vez de preferir la apropiación de dichos saldos por la entidad de crédito» no vulnera el derecho constitucional a la propiedad privada.

El encuadre competencial de los bienes vacantes quedó definitivamente fijado con la previsión introducida por la disposición final segunda de la Ley de Patrimonio del Estado de 2003. En ella se señala que los arts. 17 y 18 atinentes a los bienes inmuebles vacantes y saldos abandonados - se dictan al

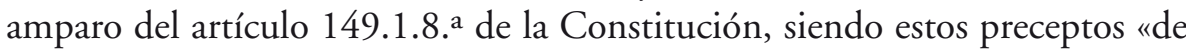
aplicación general, sin perjuicio de lo dispuesto en los Derechos civiles forales o especiales».

En el momento presente parece complejo que pueda sostenerse una competencia exclusiva del Estado para la atribución de la propiedad de los bona vacantia en virtud de los títulos competenciales del art. 149.1.14. ${ }^{\mathrm{a}}$ y $18 .^{\mathrm{a}}$ de la CE. No es tampoco evidente que la competencia exclusiva del Estado sobre legislación civil pueda limitar a las CC. AA. con derecho civil propio la posibilidad de regular esta materia sin un ulterior análisis de sus instituciones civiles. La adquisición de los bienes y los modos de adquirir, como recuerda la doctrina, constituye una materia preponderantemente civil; cuestión distinta es que la titularidad sobre aquellos se ostente por una persona jurídica pública, Estado o Administración (Lacruz Mantecón, 2011, 209 y ss.).

Desde estas claves se entiende que las SSTC 40/2018 y 41/2018 rechacen la escisión competencial que realiza el abogado del Estado entre el «establecimiento de la causa de extinción del derecho de propiedad por abandono", que admite que «sí constituye una típica norma de Derecho civil» —art. 149.1.8. ${ }^{\text {a }}$ CE—, y «la decisión normativa de atribuir la propiedad de tales bienes a una u otra entidad pública», que entiende tema ajeno y residenciado en "el título relativo a la regulación del propio patrimonio de esa Administración del art. 149.1.18. ${ }^{a}$ CE». Las razones se ofrecen en la STC 41/2018 (FJ 4), en la que se dice: «Podemos ya excluir la aplicación del 149.1.18 CE, pues las normas objeto de este proceso no se refieren al régimen de dichos bienes en su consideración de patrimoniales de una u otra Administración; esto es, no regulan nada relacionado con «el conjunto de facultades y prerrogativas que corresponden a las Administraciones públicas para la defensa y conservación de sus bienes» (STC 94/2013, de 23 de abril, FJ 414)». No queda tampoco implicada la competencia del art. 149.1.14. ${ }^{\text {a }}$ de la CE, dado que

14 En sentido contrario se manifiesta parte de la doctrina administrativista, Miguélez Fernández (2008: 277 y ss.). 
[...] los preceptos impugnados no se refieren a estos bienes desde la perspectiva que podría ser propia de dicho título competencial. Este abarca las relaciones entre las distintas haciendas (estatal, autonómicas y locales) (STC 233/1999, de 16 de diciembre, FFJJ 4 y 5) y el sistema de ingresos públicos (tributarios o de otro tipo) (STC 192/2000, de 13 de julio, FJ 6), lo que es ajeno a lo aquí discutido. Los preceptos impugnados no contemplan estos bienes en cuanto susceptibles de generar recursos a la hacienda autonómica mediante la obtención de ingresos a partir del patrimonio propio, sino, exclusivamente, desde la perspectiva de su atribución de la titularidad para el ejercicio de una actuación sectorial, la relativa a la concentración parcelaria (STC 41/2018, FJ 3).

Para las SSTC 40/2018 (FJ 5) y 41/2018 (FJ 4) resulta indiscutible que la naturaleza y el destino de estos bienes inmuebles vacantes es una materia propia de la legislación civil, lo que determina la aplicación aquilatada y expuesta de la doctrina sobre el art. 149.1.8. ${ }^{a} \mathrm{CE}^{15}$. De ahí que el núcleo central para valorar la constitucionalidad de esas disposiciones radique en su acomodación al concepto constitucional de "desarrollo» del derecho civil propio, que supone la conexión positiva de la innovación normativa con las instituciones civiles forales preexistentes (SSTC 40/ 2018 [FJ 5] y 41/2018 [FJ 4]).

\section{CONEXIÓN «ORGÁNICA»O «INSTITUCIONAL»PARA EL «DESARROLLO» NORMATIVO SOBRE BIENES VACANTES}

\subsection{Justificación de los arts. 15 y 16 de la Ley Foral 14/2007: Ilamamiento legal a la Comunidad Foral y régimen patrimonial del Fuero Nuevo de Navarra}

La amplia regulación patrimonial que contiene el Fuero Nuevo o Compilación de Derecho Civil Foral de Navarra, desde su redacción originaria por Ley $1 / 1973$, auguraba una fundamentación suficiente para considerar que los arts. 15 y 16 de LFPN constituían un «desarrollo» del derecho civil navarro, al margen de que supusieran una reiteración de los arts. 21 y 22 de la LPAP con cambio de atribución de esos bienes a la Comunidad Foral de Navarra; reduplicación normativa que, como reconoce la propia STC 40/2018, puede criticarse como «un defecto de técnica legislativa» pero no constituye «un problema de vulneración constitucional» (FJ 8).

15 La STC 40/2018 niega, siguiendo la doctrina del TC sobre el alcance de la disposición adicional primera $\mathrm{CE}$, que el carácter de competencia histórica del derecho civil de Navarra le permita a esta Comunidad Foral ir más allá de lo marcado por la doctrina constitucional sobre el art. 149.1.8. ${ }^{\text {a }} \mathrm{CE}$. 
Esa visión de la «conexión orgánica» institucional, que habilita el «desarrollo» del derecho civil propio con la innovación de sus contenidos, es la que se ha asumido en la STC 40/2018, con el trasfondo del enfrentamiento de la visión civil-administrativa sobre los bienes mostrencos y la calificación de la materia como civil.

Los anclajes institucionales en los que se ha sustentado el ajuste constitucional, en el caso de Navarra, se han centrado en tres núcleos institucionales.

En primer lugar, la regulación que contiene la ley 304.7 del Fuero Nuevo de Navarra sobre el llamamiento intestado, en la redacción originaria, a la «Diputación Foral de Navarra» y, tras la reforma de 1987, a la Comunidad Foral de Navarra; previsiones que entroncan con la controvertida aplicación de la Ley de Mostrencos de 1935 en Navarra, singularmente de los bienes abintestato, en virtud de las previsiones del art. 2 de la Ley Paccionada de 1841 (De Tudela, 1943: 330 y ss.; Fairén Guillén, 1945: 99 y ss.).

Para la STC 40/2018 la citada ley 304.7 del Fuero Nuevo ofrece una "conexión suficiente entre las figuras de los inmuebles vacantes y depósitos y saldos abandonados con los vacantes abintestatos, que no dejan de pertenecer a una misma clase o institución, que es la de los bienes abandonados y sin dueño conocido». En este sentido se reconoce que "existen dos clases de bienes vacantes, los que no tienen dueño conocido y los que aun teniéndolo, dejan de tenerlo por haber fallecido su titular sin herederos testamentarios o intestados. La Compilación de Navarra regula este segundo tipo de bienes vacantes, lo que implica una conexión con el primero y justifica la competencia en materia civil, de acuerdo con la doctrina de la conectividad formulada por este Tribunal respecto a la interpretación del artículo 149.1.8 CE».

La argumentación reseñada parte de la consideración de que la regulación de los bienes mostrencos y el llamamiento abintestato del Estado, recogidos conjuntamente en la Ley de Mostrencos de 1935, comparten un mismo fundamento y naturaleza. Como señala Lacruz Mantecón, el llamamiento en la sucesión intestada al Estado o la Administración como último destinatario obedece a la misma situación que se da cuando el bien mostrenco es abandonado por su titular, se pierde o se ignora su titularidad; los bienes hereditarios dejan de tener dueño con la muerte de su titular y no son adquiridos por nadie, porque no hay nadie para heredar o, si lo hay, no quiere hacerlo (Lacruz Mantecón, 2017: 9-10). Ese llamamiento al Estado o la Administración en la sucesión legal no se fundamenta en la presunta voluntad del causante, sino en la necesidad de responder al problema de la vacancia de un conjunto de relaciones que carecen de titular.

Una segunda conexión institucional estimada ha sido la proyección de la citada regulación sobre un instituto propio del derecho civil foral navarro como es el de los «bienes», y en particular, la propiedad y la posesión de las co- 
sas disciplinadas en el Fuero Nuevo de Navarra. De ella se deduce «una relación entre la atribución de los bienes mostrencos y el Derecho propio de Navarra que legitima constitucionalmente su regulación por los preceptos impugnados, y que no puede considerarse ajena o desvinculada del Derecho civil foral, sino más bien como una norma que se incardina en su Derecho patrimonial». La prueba de ello se halla en el propio contenido de la Compilación, que «ordena los bienes [libro tercero del Fuero Nuevo] y la propiedad y posesión de las cosas [título I del libro tercero del Fuero Nuevo] y, en particular, la adquisición de la propiedad [ley 355 del Fuero Nuevo] y la usucapión [leyes 356 del Fuero Nuevo y siguientes], incluso respecto de los bienes de las entidades públicas [ley 358 del Fuero Nuevo]».

El tercer anclaje institucional, de singular relevancia en la valoración de la existencia de una conexión orgánica que faculte el "desarrollo» legislativo, ha radicado en el hecho de que la ley 355 del Fuero Nuevo prevea, «entre los modos de adquirir la propiedad, la adquisición por disposición de la ley. Por ello, si el Fuero Nuevo regula, con carácter general, los modos de adquirir la propiedad, no pueden tacharse de inconexos aquellos preceptos forales que desarrollan dicha previsión, aunque la innoven parcialmente».

La conclusión, con el voto discrepante de cuatro magistrados, cuyo contenido se desarrolla en el formulado a la STC 41/2018, es que "con la regulación de la adquisición de bienes inmuebles vacantes y saldos y depósitos abandonados, el legislador navarro no está creando una nueva institución, sino desarrollando la ya existente, y posee indudablemente competencia para ello».

La existencia de una conexión orgánica con instituciones compiladas y positivizadas en el derecho civil de Navarra ha sido entendida atinadamente, en este caso, como suficiente para estimar ajustada a la Constitución esta regulación de carácter civil, a pesar de que los preceptos figuren dentro de la Ley Foral de Patrimonio de Navarra, cuyo carácter de corte administrativo no borra la naturaleza propia de las normas que incorpora.

\subsection{Disposición adicional sexta de la Ley $5 / 2011$, de 10 de marzo, del Patrimonio de Aragón, y texto refundido de 2013: conexión institucional de los bienes abintestato «versus» bienes abandonados}

Una valoración pareja a la realizada en la STC 40/2018, respecto a la suficiencia de la conexión institucional y anclaje a los principios del derecho civil aragonés, se ha formulado en la STC 41/2018 respecto a las normas referidas, que reproducen el art. 205 de la Ley de Reforma y Desarrollo Agrario de 12 de enero de 1973, aprobada por Decreto 118/1973, de 12 de enero, y que atribuyen la titularidad de las fincas de reemplazo procedentes de procesos 
de concentración parcelaria, sin dueño conocido o cuyo dueño no hubiese aparecido en cierto plazo, a la Comunidad Autónoma de Aragón.

El anclaje para el "desarrollo" normativo de esos bona vacantia, que se encuadra incuestionablemente en la competencia legislativa civil, se vincula igualmente en la STC 41/2018 al régimen jurídico de los bienes «abintestato» o de sucesión intestada a favor de la comunidad, previsto en la Compilación de Derecho Civil Aragonés de 1967 e incluido en los arts. 535 y 536 del vigente Código de Derecho Foral de Aragón. La sentencia justifica la existencia de una conexión suficiente entre ese régimen de la sucesión intestada y la atribución de los inmuebles vacantes resultantes de la concentración parcelaria (Latorre Vila, 2012: 213 y ss.; Lacruz Mantecón, 2012: 29 y ss.), remitiéndose a la argumentación ofrecida sobre el tema en la STC 40/2018, sin abundar en ulteriores argumentos.

De especial interés son, sin embargo, las apreciaciones contenidas en el voto particular, reflejo de las visiones contrapuestas sobre el juicio positivo de la conexión institucional; vinculada, en ocasiones, al sistema en su conjunto y exigida, en otros casos, con plena identidad.

Para los magistrados discrepantes, aunque no se diga así, debería haber existido una total coincidencia institucional para aceptar como «desarrollo» la regulación introducida. Entienden que las regulaciones de los bona abintestato y los bona vacantia obedecen a figuras de naturaleza distinta, que se desenvuelven en contextos ajenos, apuntándose las siguientes diferencias: a) la sucesión abintestato constituye una institución típica del derecho sucesorio, en tanto que la atribución de los bienes inmuebles vacantes se relaciona con su condición de abandonados, refutándose que los bienes de abintestato sean bienes vacantes; b) la atribución al Estado de los bienes de abintestato procede del silencio del causante mientras que la de los inmuebles vacantes deviene del desconocimiento de quien sea su titular; c) los bienes de abintestato no se adquieren automáticamente por ministerio de la ley, como sucedería con los bienes inmuebles vacantes, sino derivativamente por la condición de heredero, con sus derechos y deberes, y sin que haya una decisión del legislador sobre su atribución, y d) la regulación del abintestato responde a la necesidad de cerrar el sistema sucesorio para evitar la vacancia indefinida de los bienes y preservar de este modo la seguridad jurídica, mientras que, «por el contrario, la regla atributiva de la titularidad de los vacantes en favor del Estado es la consecuencia jurídica de su abandono, que extingue el derecho de su titular sobre los mismos y los convierte, por consiguiente, en res nullius, susceptibles de apropiación».

Tales apreciaciones no dejan de ofrecer contradicciones manifiestas en ese intento de encontrar una distinción ontológica entre ambas realidades jurídicas. Se relega el hecho de que es el legislador el que ha decidido que sea 
llamado a heredar el Estado o la Administración y no otros parientes del causante o instituciones públicas o privadas. Ese llamamiento se efectúa, en último lugar, para recibir unos bienes y conjunto de relaciones que se encuentran vacantes y sin titular. Como se ha reconocido mayoritariamente por la doctrina civilista (Díez-Picazo y Gullón, 2012: 216; Lacruz Mantecón, 2017:162 y ss.; Del Pozo Sierra, 2013: 82 y ss.), al Estado con el llamamiento sucesorio intestado de cierre no se le atribuye un derecho, sino que se le impone una función, basada en un interés público de carácter objetivo, que resulta irrenunciable como la potestad de la cual deriva. Según ha indicado Chinchilla Marín, la adquisición de bienes vacantes por el Estado descansa en el principio de nulla res sine domino y la preocupación por que todo, singularmente la tierra, cuente con un propietario. De ello se deriva la necesidad de asegurar el destino dominical de los bienes, y procurárselo a los que pertenecen a las personas que mueren sin disponer su herencia y sin herederos (Chinchilla Marín, 2001: 246). Por ello, como se ha sostenido en las SSTC 40/2018 y $41 / 2018$, hay vinculación institucional entre la adquisición por el Estado o la Administración de los bienes vacantes y los adquiridos por el llamamiento intestado que, en este caso, se aprecia desde la perspectiva orgánica del sistema y su valoración funcional.

\section{BREVE REFLEXIÓN FINAL}

Las garantías de la foralidad y conexión institucional orgánica, exigidas por el Tribunal Constitucional para el «desarrollo» del derecho civil propio ex art. 149.1.8. ${ }^{a} \mathrm{CE}$, no han limitado que, a través de la valoración ad casum, se aquilaten esos criterios, exigiéndose una «conexión institucional» de solo posible apreciación si el derecho civil concernido cuenta con una tipificación institucional previa idéntica a la que se pretende regular. El pronunciamiento sobre la adopción y autotutela de la LDCG de 2006, recogido en la STC 133/2017, es un reflejo de lo expuesto.

El margen de decisión que se proporciona con ello al Tribunal Constitucional aconseja al legislador autonómico que la decisión de acometer actuaciones legislativas civiles institucionalmente innovadoras no deba soportarse en las respuestas constitucionales ofrecidas a otras leyes autonómicas, sin un previo y riguroso análisis de las especialidades normativas que se contengan en su derecho civil propio.

Por ello, el entusiasmo legislativo que las SSTC 40/2018 y 41/2018 pudieran despertar en el resto de CC. AA. que disponen de un régimen civil específico sobre la sucesión legal —Cataluña, Islas Baleares, País Vasco y Galicia- solo el futuro nos dirá si resulta fundado; y si tal conexión institucional, 
entendida desde una perspectiva orgánica general, es suficiente para valorar como constitucional la posible regulación que se acometa sobre los bona vacantia sitos en cada territorio, dado el juicio que se expone en los votos particulares de las citadas sentencias.

\section{Bibliografía}

Acedo Penco, A. (2010). Derecho civil autonómico versus Derecho civil estatal: estado de la cuestión tras la sentencia del Tribunal Constitucional 31/2010, de 28 de junio. Anuario de la Facultad de Derecho de Extremadura, 38, 245-259.

Álvarez Lata, N. (2008). Sobre la eventual inconstitucionalidad de algunos preceptos de la Ley 2/2006, de 14 de junio, de Derecho Civil de Galicia. Juicio crítico a la luz de los principios del Derecho civil gallego (y de la doctrina del Tribunal Constitucional). Derecho Privado y Constitución, 22, 57-94.

Amat Llombart, P. (2017). La competencia legislativa en materia de Derecho civil del artículo 149.1.8. a de la Constitución Española. Disfunciones en torno al Derecho civil valenciano e interpretación del Tribunal Constitucional. Indret, 4. Disponible en: http://www.indret.com/pdf/1347.pdf.

Arroyo Amayuelas, E. (2010). Competència autonómica, competencia entre ordenaments jurìdics i codificació del dret civil català: un balanç. Revista de Dret Històric Català, 10, 167-213. Disponible en: https://bit.ly/2I9bn4p.

Badosa Coll, F. (2010). Sentencia 31/2010, de 28 de junio. Revista Catalana de Dret Públic, Especial Sentència 31/2010 del Tribunal Constitucional, sobre l'Estatut d'autonomia de Catalunya de 2006, 332-340. Disponible en: https://bit.ly/2QV8msC.

Bercovitz Rodríguez-Cano, R. (1971). Los efectos sucesorios de la adopción. Anuario de Derecho civil, 3, 929-969.

(1993). La conservación, modificación y desarrollo por las comunidades autónomas de los Derechos civiles, forales o especiales. Derecho Privado y Constitución, 1, 1582.

- (2016). Alto al Derecho civil valenciano. Revista Doctrinal Aranzadi Civil-Mercantil, 7. Disponible en: http:// aranzadi.aranzadidigital.es (BIB 2016121326).

— (2017). ¿ ¿Suma y sigue? Revista Doctrinal Aranzadi Civil-Mercantil, 2. Disponible en: http:// aranzadi.aranzadidigital.es (BIB 2017\10737).

- (2018a). El desarrollo del Derecho Civil gallego y la costumbre. Revista Doctrinal Aranzadi Civil-Mercantil, 2. Disponible en: http:// aranzadi.aranzadidigital.es (BIB 201815948).

— (2018b). El requisito de la conexión para el desarrollo de los Derechos civiles forales o especiales. Revista Doctrinal Aranzadi Civil-Mercantil. 7. Disponible en: http:// aranzadi.aranzadidigital.es (BIB 2018\10232).

De Verda y Beamonte, J. R. (2017). ¿Qué es lo que queda del Derecho civil valenciano en materia de familia? Derecho Privado y Constitución, 31, 111-162.

Chinchilla Marín, M. C. (2001). Bienes patrimoniales del Estado. Madrid: Marcial Pons. 
- (2004). Adquisición de bienes y derechos. En C. Chinchilla Marín (coord.). Comentarios a la Ley 33/2003, del Patrimonio de las Administraciones Públicas (pp. 149 y ss.). Madrid: Thomson-Civitas.

De Tudela, J. (1943). La sucesión ab-intestato en Navarra. Príncipe de Viana, 12, 329336.

Del Pozo Sierra, B. (2013). La compatibilidad jurídica entre el derecho del Estado en la sucesión intestada y como titular de bienes vacantes. Madrid: Dykinson.

Díaz Martínez, A. (2008). Artículo 27. En A. I. Rebolledo Varela (coord.). Comentarios a la Ley de Derecho civil de Galicia. Ley 2/2006, de 14 de junio (pp. 175 y ss.). Cizur Menor: Thomson-Reuters.

Díez-Picazo y Gullón, L. (2012). Sistema de Derecho civil, IV. Madrid: Tecnos.

Egea Fernández, J. (2010). Competencia en materia de Derecho civil. Revista Catalana de Dret Públic, Especial Sentència 31/2010 del Tribunal Constitucional, sobre l'Estatut d'autonomia de Catalunya de 2006, 2010, 332-339.

Egusquiza Balmaseda, M. A. (2007). Constitución, amejoramiento y Derecho civil navarro. Derecho Privado y Constitución, 21, 229-274.

Fairén Guillén, V. (1945). Ensayo sobre la evolución del Derecho de Navarra. Desde la guerra de la sucesión al Código civil. Príncipe de Viana, 18, 87-111.

Fernández Urzainqui, F. J. (1990). Adopción y prohijamiento en el Derecho civil navarro (Comentario a las leyes 73 y 74 del Fuero Nuevo). Revista Jurídica de Navarra, 9, 61-85. Disponible en: https://bit.ly/2Dyd38K.

García Cantero, G. (1965). La adquisición de inmuebles vacantes por el Estado. Revista de Administración Pública, 47, 9-78.

(1971). El nuevo régimen de la adopción. Anuario de Derecho civil, 3, 789-861.

García Rubio, M. P. (2017). Presente y futuro del Derecho civil español en clave de competencias normativas. Revista de Derecho Civil, 4 (3), 1-33. Disponible en: https:// www.nreg.es/ojs/index.php/RDC/article/view/276.

Lacruz Berdejo, J. L. (1984). Elementos de Derecho civil, IV. Barcelona: Bosch. (1988). Elementos de Derecho civil, III. Barcelona: Bosch.

Lacruz Mantecón, M. (2011). La ocupación imposible. Historia y régimen jurídico de los inmuebles mostrencos. Madrid: Dykinson.

- (2012). Bienes sin dueño: mostrencos y abintestatos en la nueva Ley de patrimonio aragonesa (Ley de Aragón 5/2011, de 10 de marzo). Revista Aragonesa de Administración Pública, 39-40, 11-48.

- (2017). La sucesión legal del Estado. Madrid: Reus.

Latorre Vila, L. (2012). La propiedad de las llamadas fincas de reemplazo vacantes: el recurso de inconstitucionalidad contra la disposición adicional sexta de la Ley 5/2011, de 10 de marzo, del patrimonio de Aragón. Revista de Derecho Civil Aragonés, $18,185-226$.

Miguélez Fernández, M. B. (2008). Artículo 17. En J. Fuentes Bajardi (dir.). Comentarios a la Ley del Patrimonio de las Administraciones Pública (pp. 277 y ss.). Cizur Menor: Thomson-Aranzadi.

Navas Navarro, S. (1994). La adquisición de los bienes inmuebles sin dueño conocido por la Generalidad de Cataluña. Revista Jurídica de Cataluña, 1, 9-42. 
Nieto Alonso, A. (2008). Artículo 42. En A. L. Rebolledo Varela (coord.) Comentarios a la Ley de Derecho civil de Galicia. Ley 2/2006, de 14 de junio (240 y ss.). Cizur Menor: Thomson-Reuters.

Palao Gil, F. J. (2017). We cannot turn the clock back: rigidez constitucional, formalismo jurídico y Derecho civil valenciano. Derecho Privado y Constitución, 31, 163-216.

Pantaleón Prieto, F. (1987). Artículo 610. En M. Albaladejo García (dir.). Comentarios al Código civil y Compilaciones forales, 8, 1 (pp. 135 y ss.). Madrid: Edersa.

Ragel Sánchez, L. F. (2005). Las competencias legislativas en materia de Derecho civil y su deseable reforma constitucional. Revista de Derecho Privado, 89, 3-18.

Rebolledo Varela, A. L., (2000). El Derecho civil de Galicia. En R. Bercovitz Rodríguez-Cano y J. Martínez Simancas (dirs.). Derechos civiles de España, 4 (pp. 1702 y ss.). Elcano-Navarra: Sopec.

Roca Trías, E. (2010). Competencia en materia de Derecho civil. Revista Catalana de Dret Públic, Especial Sentència 31/2010 del Tribunal Constitucional, sobre l'Estatut d'autonomia de Catalunya de 2006, 1, 346-351. Disponible en https://bit. ly/2DqlpiY.

Rodríguez Carbajo, J. R. (1985). La competencia de las comunidades autónomas para legislar sobre su patrimonio y límites de la misma. Los inmuebles vacantes pertenecen al Estado y no a las Comunidades autónomas. Anuario de Derecho civil, 38, 182 y ss.

Ruiz-Rico Ruiz-Morón, J. (2002). Leyes 73 y 74. En E. Rubio Torrano (dir.). Comentarios al Fuero Nuevo. Compilación del Derecho Civil Foral de Navarra (pp. 216-220). Cizur Mayor: Gobierno de Navarra-Aranzadi Thomson.

Sánchez Aristi, R. (2000). La adquisición por ley de la propiedad y los demás derechos reales sobre bienes. Aranzadi Civil, 3, 2435-2474.

Sande García, P. (2008). Artículo 2. En A. L. Rebolledo Varela (coord.). Comentarios a la Ley de Derecho civil de Galicia. Ley 2/2006, de 14 de junio (pp. 69 y ss.). Cizur Menor: Thomson-Reuters.

Sarmiento Méndez, X. A. (2007). Derecho autonómico y seguridad jurídica: su técnica normativa. El recurso de inconstitucionalidad contra la Ley 2/2006, de 14 de junio, de Derecho civil de Galicia. Repertorio Aranzadi del Tribunal Constitucional, 14, 1326. Disponible en: http:// aranzadi.aranzadidigital.es (BIB 2007\1815).

Valladares Rascón, E. (1976). La Ley del Patrimonio del Estado y la protección del poseedor. Revista de Derecho Privado, 60, 408-408.

Vaquer Aloy, A. (1994). Los conceptos de «conservación», «modificación» y «desarrollo» del artículo 149.1.8. a de la Constitución; su interpretación por el legislador catalán. Derecho Privado y Constitución, 2, 239-250. 